\title{
RESPIRATORY MANIFESTATIONS IN INFANTS WITH HYPOTHYROIDISM
}

\author{
BY \\ SAMIR NAJJAR \\ From the Department of Paediatrics, Faculty of Medical Sciences, American University of Beirut
}

(RECEIVED FOR PUBLICATION JULY 11, 1962)

Respiratory symptoms in infants with hypothyroidism were not emphasized as an integral part of the clinical picture until Lowrey, Aster, Carr, Ramon, Beierwaltes and Spafford (1958) pointed out the frequency with which such symptoms occurred. Of their cases, $75 \%$ had various degrees of respiratory difficulty.

The purpose of this report is to draw attention once more to the frequency of respiratory symptoms in hypothyroid infants, and to include these symptoms among the non-specific findings that should alert the paediatrician to the possibility of hypothyroidism, and thus lead to early diagnosis, early treatment and a better prognosis for normal mental development.

In the past year, four hypothyroid infants below the age of 1 year were seen at the American University Hospital. All of them had prominent respiratory symptoms. The records of hypothyroid infants admitted over the past eight years were examined; four infants with a definite diagnosis were found, all having symptoms referable to their respiratory system.

\section{Case Reports}

Case 1. A 5-month-old boy was admitted because of poor weight gain, constipation, abdominal distension, sluggishness, retarded physical and mental development, cold extremities and acrocyanosis. The mother stated that the boy 'was born with a cold' that caused nasal obstruction; this cleared spontaneously a few weeks before admission. Two older siblings are known to be hypothyroidic.

On examination he had cretinoid facies, carotenaemia, hoarseness and cold skin with mottling. His length was $56 \mathrm{~cm}$. The serum protein-bound iodine was $2 \mu \mathrm{g}$./ $100 \mathrm{ml}$. There were no calcifications in the distal femoral epiphyses.

Case 2. A 3-month-old boy was admitted because of excessive lethargy, hoarse voice, retarded motor and mental development, failure to gain weight, feeding difficulties, mild constipation and abdominal distension. In addition, the baby had had moderate-to-marked nasal obstruction since birth, causing respiratory distress at times.

On examination he had cretinoid facies, large tongue, a hoarse voice, cool, dry and mottled skin, flabby musculature and a distended abdomen. He also had noisy respiration with a profuse, mucoid, postnasal discharge. His height was $59 \mathrm{~cm}$. The serum proteinbound iodine was $2 \cdot 2 \mu \mathrm{g}$. $/ 100 \mathrm{ml}$. The distal femoral epiphyses were faintly calcified.

Case 3. A baby girl was born at the University Hospital as one of apparently uniovular twins. At the age of 15 days she started to have a nasal discharge that gradually became profuse and caused respiratory embarrassment. It did not respond to antibiotic and decongestant therapy. At the age of 67 days hypothyroidism was suspected because of sluggishness, lethargy, constipation and hoarseness. She continued to have the profuse nasal discharge, respiratory embarrassment with cyanotic episodes and developed pneumonia which was demonstrated by radiograph.

Physical examination revealed a large tongue, hoarse voice, cold skin, distended abdomen, umbilical hernia as well as a profuse sticky, greenish, nasal discharge. Referred rhonchi and coarse râles were heard over both lung fields.

At the age of 67 days the serum protein-bound iodine was $1.5 \mu \mathrm{g} . / 100 \mathrm{ml}$. There was a pinpoint calcification in the area of the distal femoral epiphysis.

Case 4. A 7-month-old boy was admitted because of constipation, distended abdomen, retarded physical and mental development, large tongue, dry skin, cold extremities and lethargy. It was also noted that he had had frequent upper respiratory infections.

On examination he had cretinoid facies, marked hypotonia, dry skin, distended abdomen and an umbilical hernia. His length was $58 \mathrm{~cm}$. The serum cholesterol was $217 \mathrm{mg} . / 100 \mathrm{ml}$. and alkaline phosphatase 2.5 Bodansky units. The distal femoral epiphyses were not seen.

Case 5. A $7 \frac{1}{2}$-month-old boy was admitted because of constipation, retarded growth, poor weight gain, sluggishness and poor development. The mother complained that the child had had noisy respiration since birth, both 
awake and asleep, and was a mouth breather because of nasal obstruction.

On examination he had cretinoid facies, dry rough scaly skin, dry hair, a large tongue, a distended abdomen, an umbilical hernia and hypotonic musculature. He also had noisy breathing; the nose and throat were filled with a mucoid discharge. His length was $57 \mathrm{~cm}$. The serum protein-bound iodine was $0.4 \mu \mathrm{g} . / 100 \mathrm{ml}$. The only epiphyseal nuclei shown on the radiograph were those of the distal femoral epiphyses.

Case 6. A 4-month-old girl was admitted because of constipation, abdominal distension and failure to grow. She had difficulty in breathing, her respiration was noisy, and her mouth was constantly open; the onset of the respiratory symptoms was not specified.

On examination she had a thick coarse dry skin, heavy features, macroglossia, hoarse voice and a distended abdomen. Her height was $55 \mathrm{~cm}$. The serum cholesterol was $264 \mathrm{mg} . / 100 \mathrm{ml}$.

Case 7. A 9-month-old girl was admitted because of a mass in the neck since birth, which had been enlarging. She also had a hoarse voice and a prominent tongue. She had no constipation, lethargy or mental retardation. She had repeated upper respiratory infections associated with cough.

On examination she had a mild macroglossia, hoarse voice and slightly distended abdomen. But she was alert and active; her skin was warm. The thyroid gland was diffusely enlarged, not nodular, but rather cystic in consistency.

The serum protein-bound iodine was $3.0 \mu \mathrm{g} . / 100 \mathrm{ml}$. A chest radiograph showed bilateral basal pneumonia.

Case 8. A $10 \frac{1}{2}$-month-old boy was admitted for follow-up treatment of his hypothyroidism. At 5 days of age he developed a "cold' with a runny nose and a cough. He was seen by several physicians who prescribed various medications, but with little help. Sluggishness, constipation and very poor feeding was noted at about the age of 3 weeks. Later his skin was seen to be thick, and his cry was weak. He gained poorly in weight. Two months before admission he was diagnosed as hypothyroid and he was started on thyroid extract therapy following which most of the symptoms disappeared and improvement was remarkable.

The only abnormalities on physical examination were the delayed linear growth (his height was $65 \mathrm{~cm}$.) and the retarded motor development.

Tables 1 and 2 summarize the symptoms and physical findings of the eight infants forming the subject of this report. Table 3 summarizes the onset, the symptoms and the signs of the respiratory manifestations. After treatment with thyroid extract, the respiratory manifestations in all eight infants disappeared promptly; many of them had been treated with antibiotics and various non-specific measures with no avail before making the diagnosis of hypothyroidism.

\section{Discussion}

The importance of early diagnosis and treatment of hypothyroidism for a more satisfactory prognosis cannot be overemphasized. If one waits for the typical, advanced picture to develop there will be an inevitable delay in the diagnosis and institution of therapy, a delay that is detrimental to normal mental development. To avoid such a delay, the paediatrician has to rely on the presence of certain non-specific symptoms, or better on a group of such symptoms to give him a clue to the possibility of hypothyroidism which could then be confirmed by laboratory means (Lowrey et al., 1958). Respiratory symptoms are among such non-specific findings in hypothyroid infants. They are of particular importance because of their frequency $(75 \%$ of Lowrey's cases, and all eight cases reported above) and because of their early onset. In the above cases three infants had symptoms from birth according to their parents (Cases 1, 2 and 5), one at the age of 5 days (Case 8). An infant under observation in hospital began having respiratory difficulty at the age of 15 days (Case 3 ). In the chart of one infant (Case 6) the onset of respiratory difficulty per se was not specified, but all the symptoms started at birth and he was only 4 months old when diagnosed. The onset of symptoms in Cases 4 and 7 is not specified.

The respiratory symptoms varied in severity from an obstructed nose or recurrent upper respiratory infection, to severe obstructive symptoms with cyanosis. There was radiological evidence of pneumonia in two infants. The nose seems to be the organ most affected, and nasal obstruction and discharge are the commonest symptoms. Proud and Lange (1957) studied the effect of surgicallyinduced hypothyroidism on the nasal mucosa of the dog. They found mucosal thickening, especially in the basal layers, loss of cilia, swelling of the collagen fibres, metaplasia of the seromucinous ducts, a tendency to squamification, and evidence of acute and chronic inflammation. They postulated that loss of cilia would lead to stagnation of secretions and predispose to infection, the squamification being a reaction to the infection. The swelling and the increased thickening of the mucosa would be additional factors in nasal obstruction. Probably the same changes take place in the mucous membranes of the rest of the respiratory tree and account for the ensuing changes. Moreover, G. Fisher (personal communication), using an electric nasopharyngoscope, noted increased lymphoid tissue with excessive mucus in the nasopharynx of older hypothyroid children, causing various degrees of respiratory obstruction and 
TABLE 1

SYMPTOMS OF EIGHT HYPOTHYROID INFANTS

\begin{tabular}{|c|c|c|c|c|c|c|c|c|c|c|c|}
\hline $\begin{array}{lll}\text { Case } & \ldots & \ldots \\
\begin{array}{l}\text { Age (mths) } \\
\text { Sex }\end{array} & \ldots & \ldots \\
\text { Lethargy } & \ldots & \ldots \\
\text { Constipation } & \ldots & \ldots \\
\begin{array}{l}\text { Feeding problems } \\
\text { Dry and/or cold skin }\end{array} \\
\begin{array}{l}\text { Poor weight gain } \\
\text { Delayed motor development } \\
\text { Abdominal distension } \\
\text { Respiratory symptoms }\end{array}\end{array}$ & $\begin{array}{l}\cdots \\
\cdots \\
\cdots \\
\cdots \\
\cdots \\
\cdots \\
\cdots\end{array}$ & $\begin{array}{l}\cdots \\
\cdots \\
\cdots \\
\cdots \\
\cdots \\
\cdots \\
\cdots \\
\cdots\end{array}$ & $\begin{array}{l}\cdots \\
\cdots \\
\cdots \\
\cdots \\
\cdots \\
\cdots \\
\cdots \\
\cdots \\
\cdots\end{array}$ & $\begin{array}{l}1 \\
\mathbf{5} \\
\mathbf{M} \\
\mathbf{P} \\
\mathbf{P} \\
\mathbf{A} \\
\mathbf{P} \\
\mathbf{P} \\
\mathbf{P} \\
\mathbf{P} \\
\mathbf{P}\end{array}$ & $\begin{array}{c}\mathbf{2} \\
\mathbf{3} \\
\mathbf{M} \\
\mathbf{P} \\
\text { mild } \\
\mathbf{P} \\
\mathbf{A} \\
\mathbf{P} \\
\mathbf{P} \\
\mathbf{P} \\
\mathbf{P}\end{array}$ & $\begin{array}{l}\mathbf{3} \\
2 \\
\mathbf{F} \\
\mathbf{P} \\
\mathbf{P} \\
\mathbf{P} \\
\mathbf{P} \\
\mathbf{P} \\
\mathbf{P} \\
\mathbf{P} \\
\mathbf{P}\end{array}$ & $\begin{array}{l}4 \\
7 \\
\mathbf{M} \\
\mathbf{P} \\
\mathbf{P} \\
\mathbf{A} \\
\mathbf{P} \\
\mathbf{P} \\
\mathbf{P} \\
\mathbf{P} \\
\mathbf{P}\end{array}$ & $\begin{array}{l}\mathbf{5} \\
7 \frac{1}{2} \\
\mathbf{M} \\
\mathbf{P} \\
\mathbf{P} \\
\mathbf{A} \\
\mathbf{A} \\
\mathbf{P} \\
\mathbf{P} \\
\mathbf{A} \\
\mathbf{P}\end{array}$ & $\begin{array}{c}\mathbf{6} \\
\mathbf{4} \\
\mathbf{F} \\
\text { Weak cry } \\
\mathbf{P} \\
\mathbf{A} \\
\mathbf{A} \\
\mathbf{P} \\
\mathbf{P} \\
\mathbf{P} \\
\mathbf{P}\end{array}$ & $\begin{array}{l}7 \\
9 \\
\mathbf{F} \\
\mathbf{A} \\
\mathbf{A} \\
\mathbf{A} \\
\mathbf{A} \\
\mathbf{P} \\
\mathbf{P} \\
\mathbf{A} \\
\mathbf{P}\end{array}$ & $\begin{array}{c}\mathbf{8} \\
10 \frac{1}{2} \\
\mathbf{M} \\
\mathbf{P} \\
\mathbf{P} \\
\mathbf{P} \\
\mathbf{P} \\
\mathbf{P} \\
\mathbf{P} \\
\mathbf{A} \\
\mathbf{P}\end{array}$ \\
\hline
\end{tabular}

P: Symptom present.

M : Male.

A: Symptom absent.

F: Female.

TABLE 2

PHYSICAL FINDINGS IN EIGHT HYPOTHYROID INFANTS

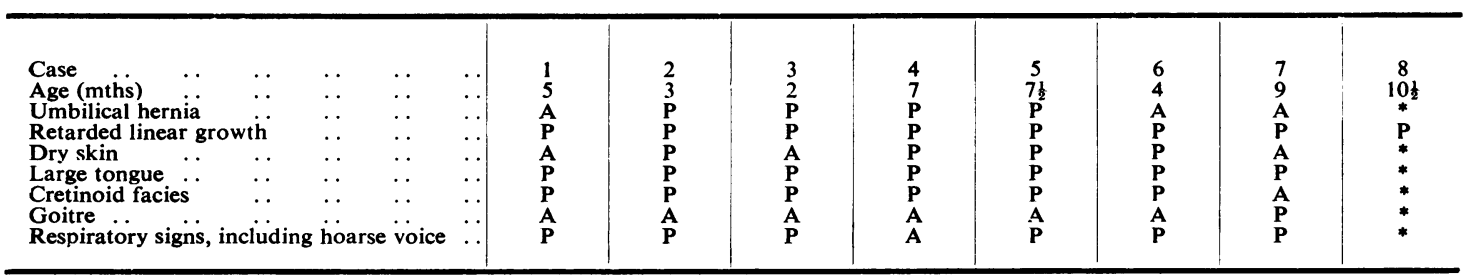

P: Physical finding present.

A: Physical finding absent.

* Infant seen two months after start of therapy.

TABLE 3

RESPIRATORY MANIFESTATIONS

\begin{tabular}{|c|c|c|c|c|}
\hline Case & Age (mths) & Age at Onset & Symptoms & Physical Findings \\
\hline 1 & 5 & Birth & Nasal obstruction lasting 4 months & Hoarse voice \\
\hline 2 & 3 & Birth & $\begin{array}{l}\text { Nasal obstruction; respiratory distress on } \\
\text { occasions }\end{array}$ & $\begin{array}{l}\text { Noisy breathing; profuse mucoid post- } \\
\text { nasal discharge }\end{array}$ \\
\hline 3 & 2 & 15 days & $\begin{array}{l}\text { Nasal discharge and obstruction; res- } \\
\text { piratory distress }\end{array}$ & $\begin{array}{l}\text { Nasal discharge; pharyngeal secretions; } \\
\text { hoarse voice; rhonchi, râles; pneu- } \\
\text { monia (x-ray) }\end{array}$ \\
\hline 4 & 7 & Not specified & Frequent upper respiratory infections & Nasal discharge \\
\hline 5 & $7 \frac{1}{2}$ & Birth & Noisy breathing; nasal obstruction & $\begin{array}{l}\text { Nose and throat filled with a mucoid } \\
\text { discharge }\end{array}$ \\
\hline 6 & 4 & Not specified & Noisy respiration; mouth kept open & Hoarse voice \\
\hline 7 & 9 & Not specified & Repeated upper respiratory infection & Hoarse voice; pneumonia (x-ray) \\
\hline 8 & $9 \frac{1}{2}$ & 5 days & $\begin{array}{l}\text { Continuous upper respiratory infection } \\
\text { until treatment started }\end{array}$ & On treatment \\
\hline
\end{tabular}

infection. These changes disappeared promptly on thyroid replacement therapy.

\section{Summary}

Eight hypothyroid infants below the age of 1 year had prominent respiratory manifestations, mainly nasal obstruction, which disappeared on thyroid replacement therapy. Respiratory symptoms should be included among the non-specific symptoms that should arouse the suspicion of hypothyroidism.

The author wishes to acknowledge gratefully the assistance of Dr. Calvin Woodruff in the preparation of the manuscript.

\section{REFERENCES}

Lowrey, G. H., Aster, R. H., Carr, F. A., Ramon, G., Beierwaltes, W. $H$ and Spafford, N. R. (1958). Early diagnostic criteria of congenital hypothyroidism. A.M.A. J. Dis. Child., $96 \quad 131$

Proud, G. O. and Lange, R. D. (1957). The effect of thyroidectomy on the nasal mucosa of experimental animals. Laryngoscope (St. Louis), 67, 201. 